\title{
RESEARCH ARTICLE \\ DEVELOPMENTAL HUMAN INTERFACE DUE TO TRAIN COLLISION OF ASIAN ELEPHANT (ELEPHAS MAXIMUS) IN WESTERN CIRCLE FOREST DIVISION, UTTARAKHAND, INDIA
}

\author{
Vimalraj Padayatchiar Govindan*, Parag Madhukar Dhakate and Ayush Uniyal \\ Uttarakhand Forest Department, Western Circle, Haldwani, Uttarakhand, India \\ *Corresponding Author E-mail: vemalrajpg@gmail.com
}

This is an open access article distributed under the Creative Commons Attribution License, which permits unrestricted use, distribution, and reproduction in any medium, provided the original work is properly cited.

\section{ARTICLE DETAILS}

Article History:

Received 01 August 2019 Accepted 04 September 2019 Available online 12 September 2019

\section{ABSTRACT}

Relation between elephant and man in India is ancient; no other animal had such a close association with the human. Pre mature elephant deaths by train collision, electrocution and drowning were common nowadays and painful disturbances in elephant population due to conflict have been described more from time to time in the outlying areas of all over India and in Uttarakhand apart from poisoning, gunfire, forest fire, diseases etc. This research paper communicates in detail cases of elephant conflict death, its root cause and its preventive actions.

\section{KEYWORDS}

Asian elephant, Train Collision, Agriculture, Conflict, Uttarakhand.

\section{INTRODUCTION}

India is one of the countries with serious problems of train- elephant/ wildlife collisions. This is because the Indian Railways (IR) is one of the world's largest railway networks, comprising $115,000 \mathrm{~km}$ of tracks over a route of about $65,000 \mathrm{~km}$ and 7500 stations. In 2015-2016, IR transported more than 22,000,000 passengers and 3,000,000 tons of freight daily. Furthermore, the Indian Railway network cuts across various forested landscapes, and its impact on wildlife and their habitats has been a matter of increasing concern [1].

Death is a natural biological phenomenon that used to happen to every living organism, it might be human or animal. But, wild animals by virtue of their less intellect compared to human being are more vulnerable to premature death [2]

Increasing population in the recent past raised the demand for more land for developmental activities and agriculture. The fragmentation and loss of wildlife habitat pushes wild animal especially elephant close to the human population and thus increasing the human-elephant interface [3].

The elephant is the largest living animal in the terrestrial environment, therefore, they need enough space and food to sustain their lives, but presently available forest cover is not sufficient to feed them and provide habitats that are way conflict death were common nowadays $[4,5]$.

Train collision or so-called "linear infrastructures" restrict the movement of wildlife populations by fragmenting their habitat, increasing edge effects, constricting ecological corridors, blocking animal movement and increasing the risk of elephant and other wildlife mortality and also these processes hinder the persistence of species in human-dominated landscapes because small and isolated wildlife/ elephant group and only limited attention has been paid to wildlife-train collisions. Therefore, there is an urgent need for more information on train- elephant/ wildlife collisions, and its mitigation.

Direct as well as indirect impacts of the railways have exacerbated over the years with the expansion of the rail network, gauge conversion, and increases in frequency and speed of trains to meet the needs of a modernizing society and an increasing population. Railway tracks pass through elephant habitat in several Indian states, including Assam, West Bengal, Uttarakhand, Jharkhand, Odisha, Kerala and Tamil Nadu, with accidents resulting in more than 200 elephant deaths yearly.
In this current research work communicates, train collision of elephants due to human developmental interface and its impact on elephant and mitigation measures like locations of collision/ accident area, understanding patterns of accidents, correlating to season, mapping elephant crossing points and their movements along the railway track and by providing suggestions for reducing the incidence of accidents.

\section{RESULTS AND DISCUSSION}

In the present study, we found that the accidental train hits of wild elephants were more common during rainy season (August to October) and always in the late night or early morning, which may be due to their normal quest to meet their daily, seasonal and annual biological needs of food, water, shelter and mates which in turn leads to a conflict death in the modern India $[6,7]$.

Previous researchers documented that there was an uneven distribution of accidents during the annual cycle, with peaks during the crop cultivation seasons and broad gauge allows trains to reach higher velocities, making it harder for elephants to avoid a moving train [8-10]. Many conflict death occurring in the same areas and none in others because of the routine migration. Also found that adult males were killed more often than other age groups and nearly three times higher than that expected because adult males range over larger areas, raid crops in villages more frequently, and thus cross railways more often than females and juveniles were killed to a lesser extent than expected, implying that they are alert and protected within a family group, whereas calves were killed more often than expected from their percentage of the population, probably because of their inability to respond quickly to dangerous situations [11]. Concentration of accidents at night [5] was probably a consequence of elephant movement patterns although only $35 \%$ of trains operate at this time this is probably because in daytime, elephants tend to rest in more dense forests, moving towards cultivated fields, villages, barren lands etc., at night $[12,13]$.

\section{CONCLUSION}

We conclude that the elephant interface over pre-mature deaths by train collision were painful disturbances in elephant population due to increased human needs, loss of elephant habitat and other associated environmental factors have been described more from time to time in the outlying areas of Uttarakhand apart from poisoning, gunfire, electrocution, forest fire, diseases etc. 
Train- elephant collisions was uneven through the landscape, reasons for this are uncertain, but it may be the result of a number of factors, such as a variation in animal abundance, activity, and behaviour, habitat distribution, landscape topography, and rail design.

In our case, accidents seemed concentrated in areas where the railway track crossed forested habitats heavily used by elephants, and in areas where elephants cross from forests to agricultural areas during their foraging movements. There is probably also a high risk of collisions in corridors that are used when animals move/migrate among forest patches areas where the risk of collision is high and new railway lines should not be laid. Where new lines are unavoidable, or where lines are already in operation, efforts should be targeted to mitigating impacts by implementing measures such as fencing, bridges, under/ overpasses and local topography. Use of communications technology as an advance warning to train drivers and signaling staff. Implement garbage clearance and ensure better visibility along the track. Providing barricade/ boulder to prevent accident of elephants. Setting up of long term funding, vegetation and animal monitoring projects. Specific programmes, research and development in the field to restore ecosystem. Sensitization of organisations and local community mobilization required.

All these processes should be conducted by technically qualified agencies in close collaboration with local and regional stakeholders, including government, NGOs, and the general public for the safety of wildlife and its ecosystem.

\section{ACKNOWLEDGEMENTS}

We would like to thank the Conservator of Forest and Divisional Forest Officers, Veterinary officers and other staffs of Western Circle, Haldwani giving me the opportunity for this study.

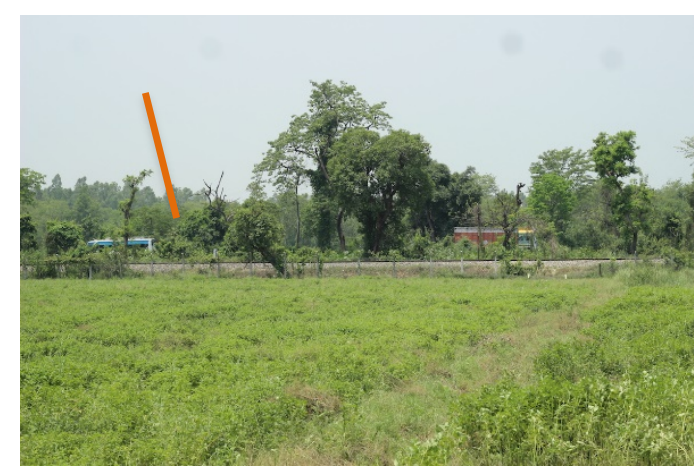

Figure 1: Agricultural land near Rail/NH track

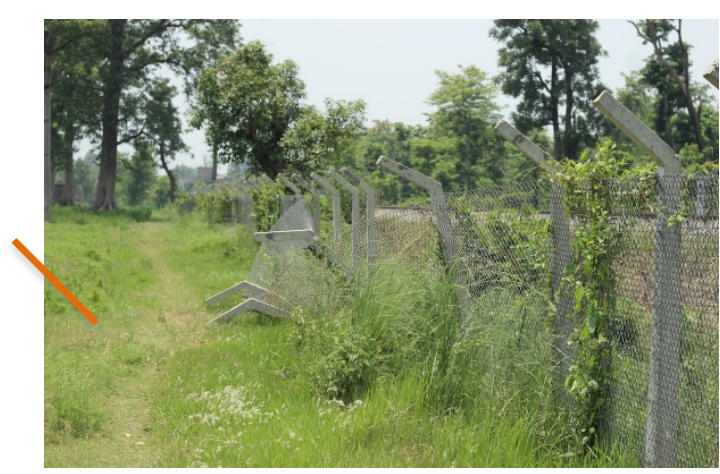

Figure 2: Fence breach by elephants

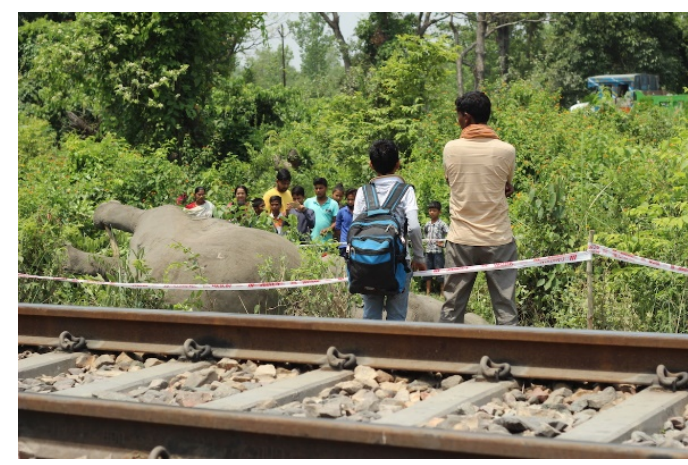

Figure 3: Conflict death near Rail track

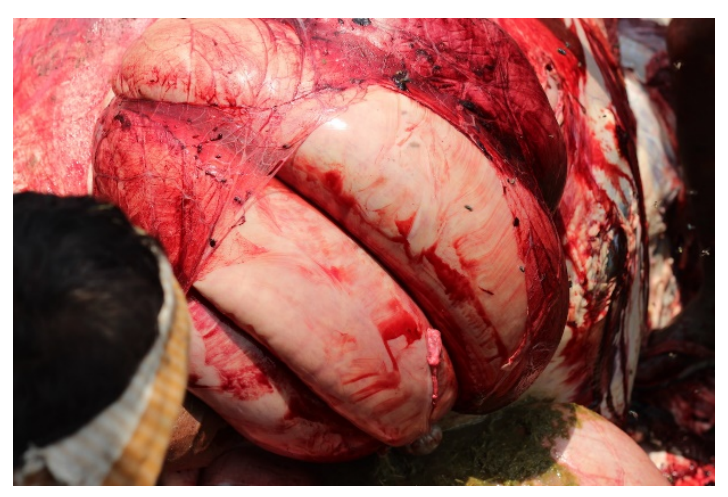

Figure 4: Severe internal bleeding-train collision

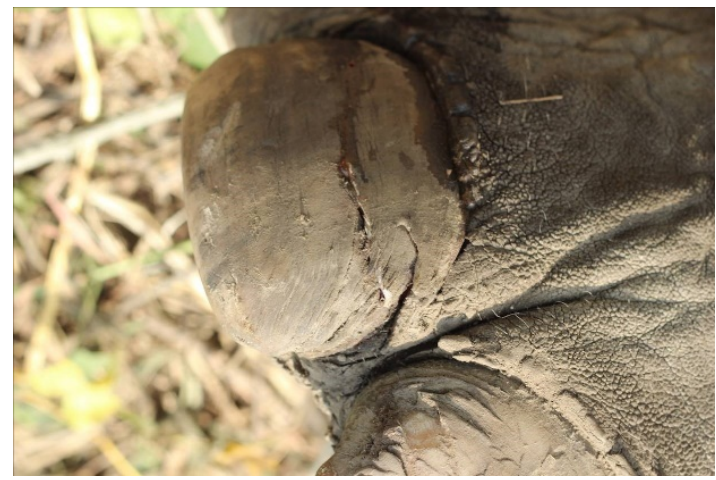

Figure 5: Nail injury due to train collision

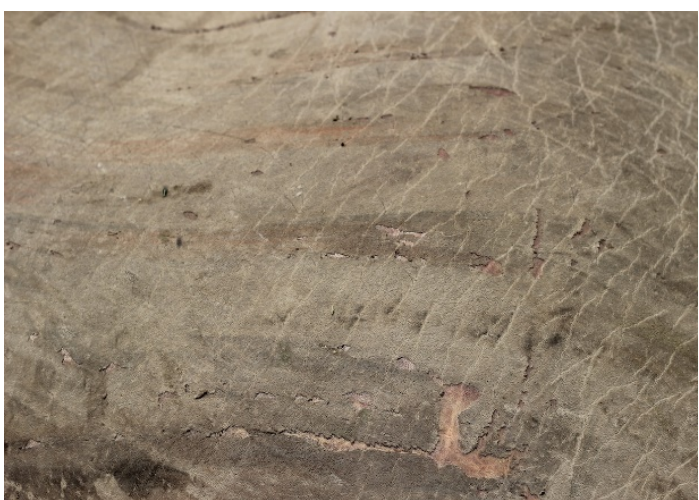

Figure 6: Severe skin laceration- train collision

\section{REFERENCES}

[1] 2014.http://indianrailways.gov.in/railwayboard/uploads/ directorate/st at_econ/IRSP_201314/pdf/Statistical_Summary/Summary \%20Sheet_Eng.pdf. Indian Railways. Staistical summary-Indian railways. Retrieved November 05, 2016.

[2] Parker, G. 2007. A Training Course for Community-Based Approaches in Africa. Sub-Saharan Africa: IUCN.

[3] Radha, S., Sanjoy, A. 2012. An analysis of elephant death in buxa tiger reserve area of West Bengal, India, Geo-Analys, 2(2), 151-156.

[4] Gunawardhana, L.M.A.P. 2018. An analysis of Human-Elephant conflict as a disaster: A case study in Anuradhapura district of Sri Lanka, Journal of Tropical Environment I, 40-55.

[5] Karthick, S., Ramakrishnan, B., Illakia, M. 2018. Human-elephant conflict issues with special reference to crop damage and people's perception in and around coimbatore forest division, Southern India, Indian Forester, 142(10), 1010-1018.

[6] Caughley, G., Sinclair, A.R.E. 1994. Wildlife Ecology and Management, Cambridge, Blackwell Science.

[7] Lingaraju, H.G., Venkataramana, G.V. 2014. Elephant deaths due to Human Elephant Conflict in and around Bandipur Natioanl Park, Karnataka, India. Research Journal of Animal, Veterinary and Fishery Sciences, 2(11), 7-12. 
[8] Roy, M., Sukumar, R. 2017. Railways and Wildlife: A Case Study of Train-Elephant Collisions in Northern West Bengal, India. Railway Ecology, Springer International Publishing, 157-177.

[9] Sukumar, R. 2003. The living elephants: Evolutionary ecology, behavior and conservation. New York: Oxford University Press.

[10] Sarma, U.K., Easa, P.S., Menon, V. 2006. Deadly Tracks- A scientific approach to understanding and mitigating elephant mortality due to train hits in Assam, Technical Report 24, Wildlife Trust of India, 2006.

[11] Williams, A.J.T., Johnsingh, P.R., Krausman. 2001. Elephant-Human
Conflicts, Rajaji National Park, North Western India. Wildlife Society Bulletin, 29(4), 1097-1104.

[12] Kulatunga. 2011. Early detection of wild elephants to prevent train elephant accidents, Annual Conference of International Institute for Infrastructure, Renewal and Reconstruction (IIIRR), Kandalama, Sri Lanka, 7.

[13] Ramkumar, K., Ramakrishnan, B., Karthick, S., Saravanamuthu, R. 2014. Human and elephant (Elephas Maximus) deaths due to conflict in Coimbatore Forest Division, Tamilnadu, India Zoo's Print, 29(8), 1219. 